\title{
OXIDATION BEHAVIOR OF L-THREONINE BY N-BROMOPHTHALIMIDE IN MICELLAR SYSTEM OF CTAB
}

\author{
YOKRAJ KATRE ${ }^{a}$, NAMITA GOYAL ${ }^{a}$, RADHIKA SHARMA ${ }^{a}$, AJAYA KUMAR SINGH \\ a Department of Chemistry, Kalyan Post Graduate College, Bhilai Nagar, Durg, Chhattisgarh 490006, India \\ ${ }^{b}$ Department of Chemistry, Government Vishwanath Yadav Tamaskar Post Graduate Autonomous College, Durg, Chhattisgarh, India
}

(Received: October 12, 2012 - Accepted: May 14, 2012)

\begin{abstract}
The effect of cationic surfactant Cetyltrimethylammonium bromide (CTAB) molecules on the oxidation of L-threonine by N- bromophthalimide (NBP) has been studied at $308 \mathrm{~K}$. The reaction exhibits first order dependence on NBP and fractional positive order on L-threonine and negative fractional order dependence on $\mathrm{HClO}_{4}$. The effects of $\mathrm{KCl}, \mathrm{KBr}$, phthalimide, mercuric acetate and dielectric constant of the medium have also been studied and summarized. CTAB strongly catalyzes the reaction and after achieving a maximum the rate remains almost constant at higher concentrations of CTAB. This micellar effect has been analyzed, plotted and results are treated quantitatively in terms of Berezin model. The various activation parameters in presence and absence of CTAB have been also evaluated. A suitable mechanism along with rate law consistent with the experimental findings has been worked out. Based on the model association rate constants have been computed.
\end{abstract}

Keywords: Micellar Kinetics, N-bromophthalimide, L-threonine, Oxidation, Berezin model

\section{INTRODUCTION}

Surfactant molecules self aggregate into supra molecular structures of higher order when dissolved in water or oil. The simplest aggregate of these surfactant molecules is called micelle. One of the most spectacular properties of surfactants is their ability to strongly influence chemical reactions either by accelerating or inhibiting the rate of reaction. Chemical reactions in micellar system resemble the enzyme catalysed reactions in many ways. That is why micellar induced reactions have established an important place not only in chemical science but also in biochemical sciences.

Oxidation of amino acids is of immense importance in the field of metabolism and medical science. This importance arises from the fact that organism strives to maintain protein balance in body by oxidation of amino acids. The periodic nature of human nutrition with cycles of fasting and feeding results in losses and gains of body proteins. This occurs from the response of protein metabolism i.e. oxidation of amino acids to dietary intake ${ }^{1}$. Also, by modulation of amino acid oxidation distinct positive effect of human growth hormone has been achieved on protein synthesis ${ }^{2}$. Hence, the mechanism by which the oxidation of various amino acids is coordinated and adjusted to match protein intake is of considerable practical importance and has been subject of various studies ${ }^{3-6}$.

L-threonine is one of the non-charged hydrophilic amino acids and this hydrophilic property implies that it is often found on the surfaces of proteins and is often the residue of epitopes for molecular recognition. In bioconjugate chemistry, oxidation of L-threonine residues at certain positions in proteins and peptides to create an aldehyde group is one of the approaches to modify proteins and peptides. Subsequently, the created aldehyde group is used to link other functional molecules? ${ }^{7}$. This modification approach appears to be successful in acidic and neutral media, but the reaction conditions such as reaction time and temperature play very important role in such modification. For instance, a long reaction time could lead to the oxidations of most of the amino acid residues in the proteins ${ }^{8}$. It is perhaps not surprising that oxidations of amino acids by various oxidants have been investigated extensively in view of the important biological consequences of the amino acids. Some of the oxidants are metal ions/complexes ${ }^{9-12}$ and others are non-metallic agents ${ }^{13-15}$. Although these oxidation reactions display diverse reaction mechanisms, concurrent deamination and decarboxylation to these amino acids are virtually found in almost all the cases.

From a technological perspective, protein-surfactant interactions are important because they modulate the functional properties of proteins. The surfactants may interact with proteins directly by competing for oil-water or air-water interfaces and binding to them, thereby, leading to substantial changes in the protein conformation. Alterations in the molecular characteristics of globular proteins due to their interactions with surfactants may lead to changes in their ability to bind other molecules, i.e. they may self-associate and be absorbed at interfaces thus altering their functional characteristics. However several details in the mode of interaction of surfactants with protein remain unanswered. Therefore it is very important to understand the origin and nature of protein-surfactant interactions both qualitatively and quantitatively. We find that studies of amino acids oxidation have been done mostly in the presence of metal ions or other catalysts ${ }^{9-15}$ and very limited literature is available for studies of amino acid oxidation in presence of micellar aggregates.

\section{EXPERIMENTAL}

A standard aqueous solution of CTAB (Sigma Aldrich, $99 \%$ purity) and L-threonine (Sigma Aldrich, purity $>98 \%$ TLC) was prepared in distilled water. NBP was used as obtained (Aldrich, $95 \%$ purity) and melting point of the sample was found to be $481 \mathrm{~K}$. Solutions of NBP were prepared in $80 \%$ distilled acetic acid and stored in a black-coated flask to prevent photochemical deterioration. The prepared NBP solution was then standardized iodometrically ${ }^{16}$ against the standard solution of sodium thiosulphate (Qualigens, AR) using starch as an indicator. A standard aqueous solution of mercuric acetate (Loba Chemie, GR) was acidified with $20 \%$ distilled acetic acid (Sd-Fine, AR). Perchloric acid (Loba Chemie, G.R.) diluted with distilled water, was standardized by standard solution of $\mathrm{NaOH}$. Water used for the preparation of all aqueous solutions was distilled three times.

Kinetic measurements. To carry out the reaction, pre-equilibrated amount of the oxidant solution i.e. [NBP] thermostated at $308 \mathrm{~K}$ was rapidly added to another bath containing required amounts of [L-threonine], [CTAB], $\left[\mathrm{Hg}(\mathrm{OAc})_{2}\right],\left[\mathrm{HClO}_{4}\right]$, and $\mathrm{CH}_{3} \mathrm{COOH}$. The progress of the reaction was followed by estimating the amount of unconsumed NBP iodometrically at regular time intervals using freshly prepared starch as indicator. The course of the reaction was studied for two half-lives.

\section{RESULT AND DISCUSSION}

To study the effects of concentration of different reactants on the kinetics of the oxidation reaction and with a view to ultimately propose suitable reaction mechanism, concentration of each reactant was varied keeping concentration of other reactants constant. The linearity of plots of log NBP versus time in each case indicates a first order reaction on NBP. All the reactions were carried out under pseudo-first order conditions by taking [L-threonine] $>$ [NBP]. A pseudo-first order rate constant has been determined in each experimental set to establish the dependence of the active reactants and thus working out the mechanism and rate law of the oxidation reaction. The results of these variations have been reported in Table 1. The role of mercuric acetate is to prevent any intervention due to $\mathrm{Br}$ ions in the reaction. So the basic function of mercuric acetate is to act as a scavenger. 
Table 1. Effect of [NBP], [L-threonine], $\left[\mathrm{Hg}^{++}\right],\left(\mathrm{CH}_{3} \mathrm{COOH}\right) \%$ and $\left[\mathrm{H}^{+}\right]$on the Oxidation reaction rate.

\begin{tabular}{|c|c|c|c|c|c|}
\hline $\begin{array}{l}{[\mathrm{NBP}] \cdot 10^{4}} \\
\text { mol.dm }\end{array}$ & $\begin{array}{c}\text { [L-threonine }] \cdot 10^{3} \\
\text { mol.dm }{ }^{-3}\end{array}$ & $\begin{array}{c}{[\mathrm{Hg}++] \cdot 10^{4}} \\
\text { mol.dm }\end{array}$ & $\underset{\%}{\mathrm{CH}_{3} \mathrm{COOH}}$ & $\begin{array}{l}{\left[\mathrm{H}^{+}\right] \cdot 10^{2}} \\
\text { mol.dm }\end{array}$ & $k_{\mathrm{obs}} \cdot 10^{4}$ \\
\hline 1.0 & 1.0 & 2.0 & 50 & 1.5 & 2.84 \\
\hline 2.0 & & & & & 2.86 \\
\hline 3.0 & & & & & 2.83 \\
\hline 4.0 & & & & & 2.84 \\
\hline 5.0 & & & & & 2.85 \\
\hline \multirow[t]{8}{*}{1.0} & 0.5 & 2.0 & 50 & 1.5 & 2.48 \\
\hline & 1.0 & & & & 2.84 \\
\hline & 1.5 & & & & 3.40 \\
\hline & 2.0 & & & & 3.81 \\
\hline & 2.5 & & & & 4.12 \\
\hline & 3.0 & & & & 4.42 \\
\hline & 3.5 & & & & 4.78 \\
\hline & 4.0 & & & & 5.12 \\
\hline \multirow[t]{4}{*}{1.0} & 1.0 & 2.0 & 50 & 1.5 & 2.86 \\
\hline & & 4.0 & & & 2.10 \\
\hline & & 6.0 & & & 1.78 \\
\hline & & 8.0 & & & 1.65 \\
\hline \multirow[t]{5}{*}{1.0} & 1.0 & 2.0 & 40 & 1.5 & 3.62 \\
\hline & & & 45 & & 3.21 \\
\hline & & & 50 & & 2.82 \\
\hline & & & 55 & & 2.51 \\
\hline & & & 60 & & 2.28 \\
\hline \multirow[t]{6}{*}{1.0} & 1.0 & 2.0 & 50 & 0.5 & 5.10 \\
\hline & & & & 1.0 & 3.71 \\
\hline & & & & 1.5 & 2.80 \\
\hline & & & & 2.0 & 2.30 \\
\hline & & & & 2.5 & 2.00 \\
\hline & & & & 3.0 & 1.76 \\
\hline
\end{tabular}

Effects of varying L-threonine. The plot of $\log k$ versus $\log \mathrm{L}$-threonine has been found to be linear with positive slope of 0.356 (Figure 1) indicating that the order with respect to L-threonine is fractional positive (Table 1). This positive effect may be attributed to increase in localized concentration of reactants at the micellar interface leading to enhanced reaction rates.

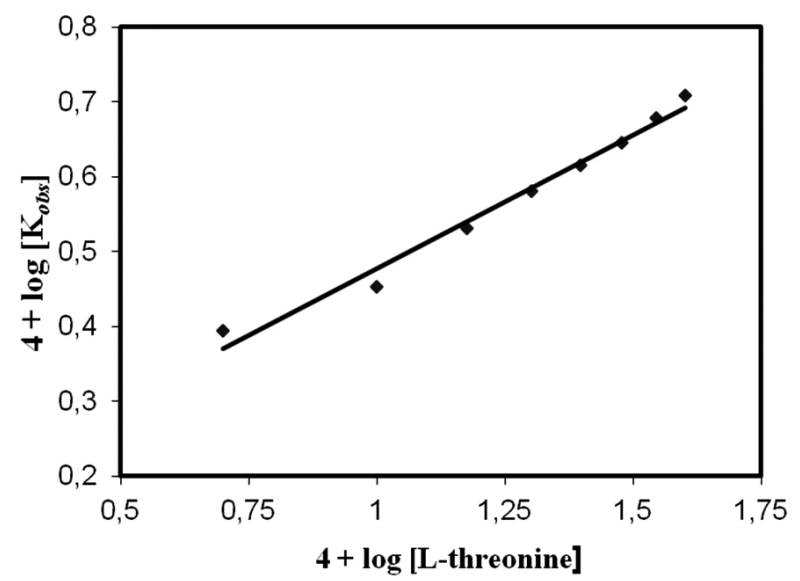

Figure1. The plot of $\log k_{o b s}$ vs. $\log$ [L-threonine] with reaction conditions as $[\mathrm{NBP}]=1.0 \times 10^{-4} \mathrm{~mol} \mathrm{dm} \mathrm{dm}^{-3},\left[\mathrm{Hg}^{++}\right]=2.0 \times 10^{-4} \mathrm{~mol} \mathrm{dm}^{-3},\left[\mathrm{H}^{+}\right]=1.5 \times 10^{-2}$ $\mathrm{mol} \mathrm{dm}{ }^{-3}[\mathrm{CTAB}]=1.0 \times 10^{-4} \mathrm{~mol} \mathrm{dm}^{-3},\left[\mathrm{CH}_{3} \mathrm{COOH}\right]=50 \%$, Temperature $=$ $308 \mathrm{~K}$
Effect of varying CTAB. The $\mathrm{CTAB}$ concentration was varied in the range of $0.5 \times 10^{-4}$ to $5.0 \times 10^{-4} \mathrm{~mol} \mathrm{dm}^{-3}$ and the rate constant values first increased from $1.91 \times 10^{-4} \mathrm{~s}^{-1}$ to $19.35 \times 10^{-4} \mathrm{~s}^{-1}$ and after that it remains almost constant on further increasing surfactant concentration (Figure 2). The results are presented in Table 4. The increase in $\mathrm{k}_{\mathrm{obs}}$ was observed even at $[\mathrm{CTAB}]<\mathrm{CMC}$. This fact is usually interpreted as reactants inducing micelle formation (surfactant molecules start aggregating below CMC). This catalysis below CMC is termed as submicellar catalysis or pre-micellar catalysis. The feasibility can be sought in the fact that small aggregates of the surfactants (dimers, trimers, tetramers, etc.) exist below CMC. These small submicellar aggregates can interact physically with the reactants forming catalytically active entities.

The maxima in the rate-surfactant profile are produced by two opposite effects. Binding of reactants in the Stern layer begins as soon as the micelle formation starts and these reactants are transferred into a small volume of the micellar pseudophase. There is thus a concentration effect which is responsible for acceleration. This concentration effect is opposed by the counterions dilution of the reactants within the micellar pseudophase with increasing surfactant concentration. The former effect is predominant at lower surfactant concentrations whereas these two counter effects are balanced at higher concentration of surfactant, resulting in constancy in rate-surfactant profile. This micellar effect on the reaction in terms of pseudophase models has been discussed separately later on.

Effect of varying $\mathrm{HClO}_{4}$ With increasing $\left[\mathrm{H}^{+}\right]$the rate constant values decreased and the order with respect to $\mathrm{H}^{+}$found to be negative fractional $(-0.602)$. The retardation by $\left[\mathrm{H}^{+}\right]$may be mainly attributed to the conversion of the more reactive neutral species of L-threonine to the less reactive protonated form. The results are presented in Table 1 and Figure 3. 


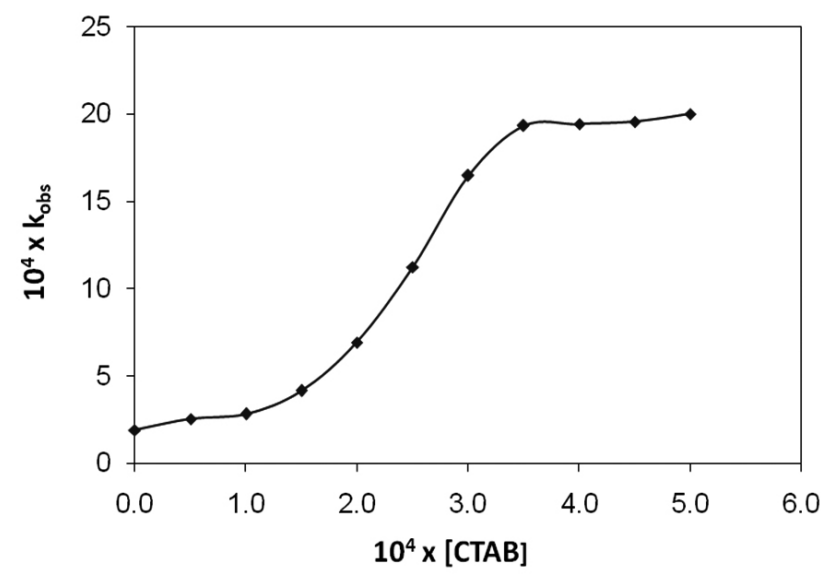

Figure 2 The plot of $\log k_{o b s}$ vs. [CTAB] with reaction conditions as $[\mathrm{NBP}]=1.0 \times 10^{-4} \mathrm{~mol} \mathrm{dm}^{-3},[\mathrm{~L}-$ threonine $]=1.0 \times 10^{-3} \mathrm{~mol} \mathrm{dm}^{-3},\left[\mathrm{H}^{+}\right]=1.5$ $\times 10^{-2} \mathrm{~mol} \mathrm{dm}^{-3}\left[\mathrm{Hg}^{++}\right]=2.0 \times 10^{-4} \mathrm{~mol} \mathrm{dm}^{-3},\left[\mathrm{CH}_{3} \mathrm{COOH}\right]=50 \%$, Temperature $=308 \mathrm{~K}$.

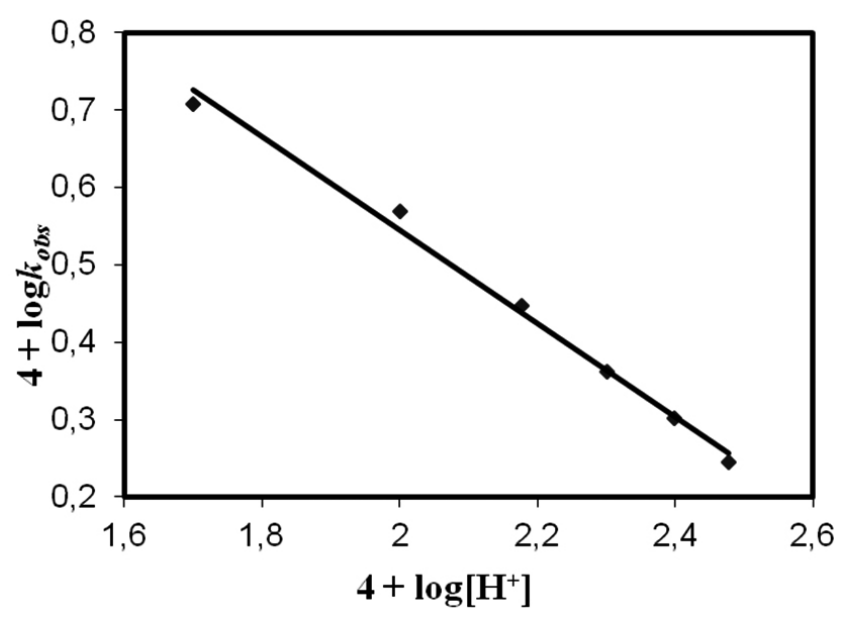

Figure 3. The plot of $\log k_{\text {obs }}$ vs. $\log \left[\mathrm{HClO}_{4}\right]$ with reaction conditions as $[\mathrm{NBP}]=1.0 \times 10^{-4} \mathrm{~mol} \mathrm{dm}^{-3},\left[\mathrm{Hg}^{++}\right]=2.0 \times 10^{-4} \mathrm{~mol} \mathrm{dm}^{-3},[\mathrm{CTAB}]=$ $1.0 \times 10^{-4} \mathrm{~mol} \mathrm{dm}^{-3}[\mathrm{~L}$-threonine $]=1.0 \times 10^{-3} \mathrm{~mol} \mathrm{dm}^{-3},\left[\mathrm{CH}_{3} \mathrm{COOH}\right]=50 \%$, Temperature $=308 \dot{\mathrm{K}}$

Effect of initially added product. The effect of phthalimide, added initially, was studied. Addition of phthalimide brought no effect on the rate of reaction. This observation helped in determining the active species of the NBP which has been discussed separately under "Mechanism".

Effect of varying dielectric constant. To study the effect of dielectric constant (polarity) of the medium on the rate of reaction, the micellar catalyzed oxidation of L-threonine by NBP was studied in various composition of acetic acid (Table 1). The results clearly reveal that the rate decreases with increase in the percentage of acetic acid, i.e. with decreasing dielectric constant of the medium.

The effect of dielectric constant of the medium on the rate constant of a reaction between two ions has been described by the well known equation ${ }^{17}$, given below

$$
\log k_{o b s}=\log K_{0}^{\prime}-\frac{Z_{A} Z_{B} e^{2} N}{2.303\left(4 \pi \varepsilon_{0}\right) d_{A B} R T} \times \frac{1}{\varepsilon}
$$

Where $\mathrm{k}_{0}$ is the rate constant in a medium of infinite dielectric constant, $Z_{A}$ and $Z_{B}$ are the charges of reacting ions, $d_{A B}$ refers to the size of activated complex, and $T$ is absolute temperature and $\varepsilon$ is the dielectric constant of the medium. Plot has been made between $\log k_{\mathrm{ob}}$ and $1 / \varepsilon$, which gave a straight line having slope equal to $-Z_{A} Z_{B} e^{2} N / 2.303\left(4 \pi \varepsilon_{0}\right) \mathrm{d}_{\mathrm{AB}} \mathrm{RT}$ (Figure 4).

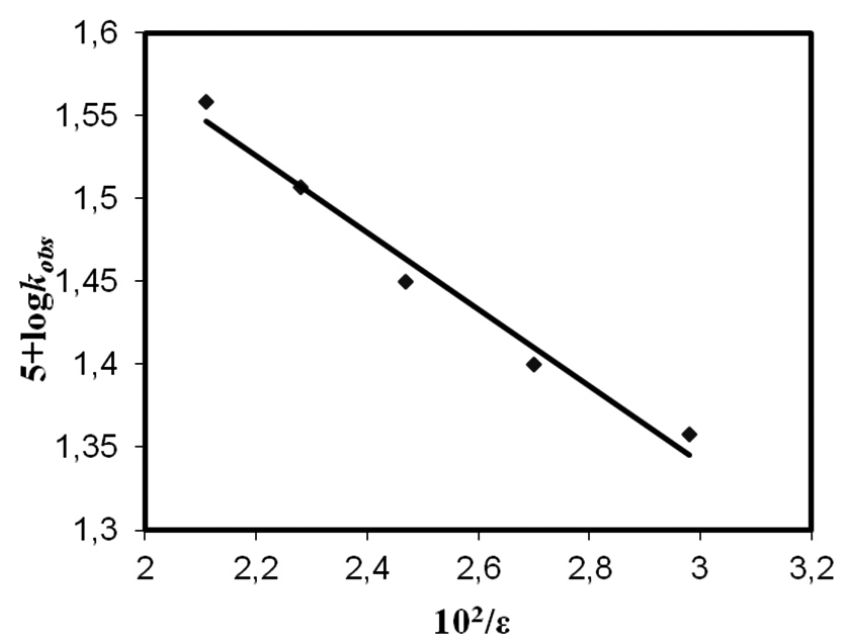

Figure 4. The plot of $\log k_{\mathrm{obs}}$ vs. $1 / \varepsilon$ with reaction conditions as $[\mathrm{NBP}]=1.0 \times 10^{-4} \mathrm{~mol} \mathrm{dm}^{-3},\left[\mathrm{Hg}^{++}\right]=2.0 \times 10^{-4} \mathrm{~mol} \mathrm{dm}^{-3}$, [L-threonine $]=$ $1.0 \times 10^{-3} \mathrm{~mol} \mathrm{dm}^{-3}[\mathrm{CTAB}]=1.0 \times 10^{-4} \mathrm{~mol} \mathrm{dm}-3,\left[\mathrm{H}^{+}\right]=1.5 \times 10^{-2} \mathrm{~mol} \mathrm{dm}^{-3}$, Temperature $=308 \mathrm{~K}$

Effect of inorganic electrolytes. The reaction rate is enhanced by addition of inorganic electrolytes (Table 2) and the rate enhancing effect largely depends upon the nature of counterions and this enhancement increases as the hydrophilic character of the salt increases.

With ionic surfactants, the addition of electrolytes such as $\mathrm{KBr}$ or $\mathrm{KCl}$ to the surrounding solution at first acts primarily to modify interactions between micelles. However, at sufficiently elevated salt concentrations micelles grow above their size in pure water. The salt effect on micellar catalysis should be considered in the light of its competition with the substrate molecule, which interacts with the micelle electrostatically and hydrophobically, and structural changes, which occur on salt addition. The effect of added salts on the rate of reaction was also explored because salts as additives, in micellar systems, acquire a special ability to induce structural changes which may, in turn, modify the substrate - surfactant interaction leading to acceleration of reaction rate.

Table 2 Effect of Inorganic electrolytes on the reaction rate.

\begin{tabular}{|c|c|c|}
\hline $\begin{array}{c}{[\mathrm{KCl}] \cdot 10^{7}} \\
\mathrm{~mol} \mathrm{dm}^{-3}\end{array}$ & $\begin{array}{c}{[\mathrm{KBr}] \cdot 10^{7}} \\
\mathrm{~mol} \mathrm{dm}{ }^{-3}\end{array}$ & $\begin{array}{c}k_{\text {obs }} \cdot 10^{4} \\
\mathrm{~s}^{-1}\end{array}$ \\
\hline 0.0 & ---- & 2.84 \\
\hline 0.5 & --- & 3.45 \\
\hline 1.0 & --- & 3.73 \\
\hline 1.5 & ---- & 4.06 \\
\hline 2.0 & ---- & 4.53 \\
\hline 2.5 & ---- & 4.91 \\
\hline---- & 0.0 & 2.84 \\
\hline---- & 0.5 & 3.66 \\
\hline---- & 1.0 & 3.90 \\
\hline---- & 1.5 & 4.23 \\
\hline---- & 2.0 & 4.51 \\
\hline---- & 2.5 & 4.78 \\
\hline
\end{tabular}

Activation parameters. The effect of temperature on rate constant was studied in the temperature range of 303-318 K. From Arrhenius plots, the values of activation energy $\left(E_{2}\right)$ were calculated and the values of $\Delta S^{\#}$ and $\Delta \mathrm{G}^{\#}$ were computed from Eyring equation and are reported in Table 3, Figure 5. A lower value of $\triangle \mathrm{E}$ in presence of CTAB shows the catalytic effect on the rate of reaction. The larger negative value of $\Delta \mathrm{S}^{\#}$ in the presence of surfactant indicates that more ordered activated complex is formed in the presence of surfactant. The fairly positive values of $\Delta \mathrm{H}^{\#}$ and $\Delta \mathrm{G}^{\#}$ indicate that the transition state is highly solvated. Nearly same value of $\Delta \mathrm{G}^{\#}$ in absence as well as in presence of the surfactant has been observed which indicates the same reaction mechanism in aqueous and micellar medium. 
Table 3. Temperature effect and activation parameters for CTAB induced reaction of oxidation of L-threonine by NBP.

\begin{tabular}{|c|c|c|}
\hline Parameters & $\begin{array}{c}\text { Without Surfactant } \\
k_{\text {obs }} \cdot 10^{4} \mathrm{~s}^{-1}\end{array}$ & $\begin{array}{c}\text { With Surfactant } \\
{[\mathrm{CTAB}]} \\
k_{\text {obs }} 10^{4} \mathrm{~s}^{-1}\end{array}$ \\
\hline $303 \mathrm{~K}$ & 1.21 & 1.92 \\
\hline $308 \mathrm{~K}$ & 1.90 & 2.84 \\
\hline $313 \mathrm{~K}$ & 3.27 & 4.72 \\
\hline $318 \mathrm{~K}$ & 4.32 & 5.61 \\
\hline$\Delta \mathrm{Ea}\left({\left.\mathrm{kJ} . \mathrm{mol}^{-1}\right)}^{1}\right)$ & 69.92 & 59.76 \\
\hline$\Delta \mathrm{H}^{\#}\left({\left.\mathrm{~kJ} . \mathrm{mol}^{-1}\right)}^{\#}\left(\mathrm{JK}^{-1} \cdot \mathrm{mol}^{-1}\right)\right.$ & 67.37 & 57.20 \\
\hline$\Delta \mathrm{G}^{\#}\left(\mathrm{~kJ} \cdot \mathrm{mol}^{-1}\right)$ & -89.29 & -118.95 \\
\hline $\mathrm{Log} \mathrm{Pz}$ & 94.87 & 93.84 \\
\hline
\end{tabular}

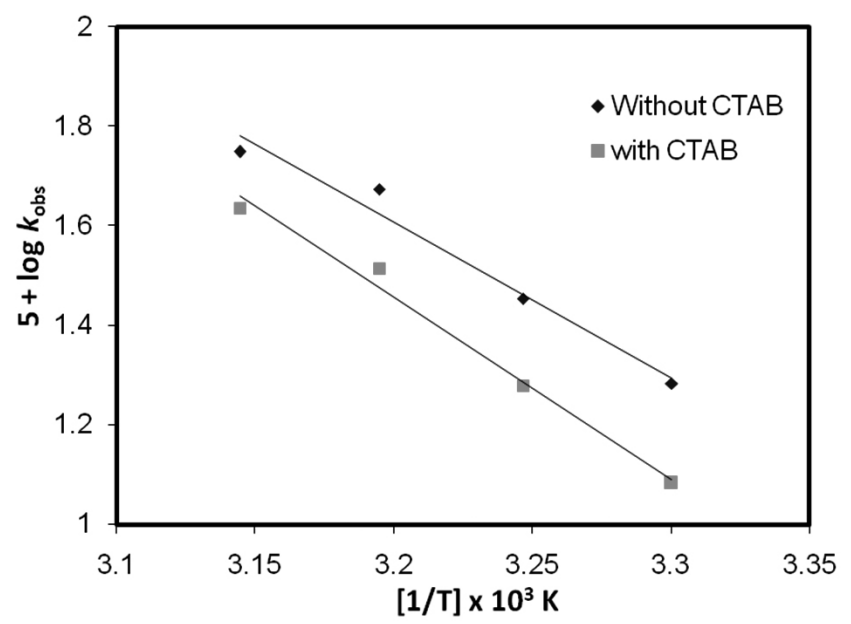

Figure 5. The plot depicting effect of temperature with reaction conditions as $[\mathrm{NBP}]=1.0 \times 10^{-4} \mathrm{~mol} \mathrm{dm}^{-3}$, $[\mathrm{L}$-threonine $]=1.0 \times 10^{-3} \mathrm{~mol} \mathrm{dm}^{-3},\left[\mathrm{H}^{+}\right]=$ $1.5 \times 10^{-2} \mathrm{~mol} \mathrm{dm}^{-3}\left[\mathrm{Hg}^{++}\right]=2.0 \times 10^{-4} \mathrm{~mol} \mathrm{dm}^{-3},\left[\mathrm{CH}_{3} \mathrm{COOH}\right]=50 \%$, [CTAB] $=1.0 \times 10^{-4} \mathrm{~mol} \mathrm{dm}^{-3}$

Mechanism. $N$-halo compounds have been used in organic synthetic methodology especially in the oxidation and bromination reactions. It has been reported earlier by several researchers ${ }^{18-21}$ that NBP is oxidizing and brominating agent because of large polarity of $>\mathrm{N}-\mathrm{Br}$ bond. NBP is capable of producing $\mathrm{Br}^{+}$reasonably shows that NBP, like other similar $N$-halo imides, may exist in various forms in acidic medium, that is, free NBP, protonated $\mathrm{NBP}, \mathrm{Br}^{+}, \mathrm{HOBr},\left(\mathrm{H}_{2} \mathrm{OBr}\right)^{+}$, as per the following equilibria:

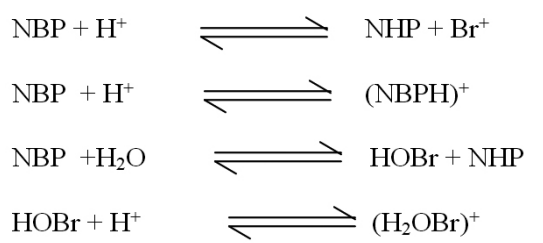

Addition of phthalimide in the reaction mixture has no effect on the rate of oxidation in acidic media. This rules out any pre-equilibrium step $(2 \& 4)$ in which phthalimide is one of the products. Hence neither $\mathrm{Br}^{+}$nor $\mathrm{HOBr}$ can be considered as reactive species. When $(\mathrm{NBPH})^{+}$or $\left(\mathrm{H}_{2} \mathrm{OBr}\right)^{+}$is taken as the reactive species, the rate law obtained shows first order kinetics with respect to hydrogen ion concentrations, contrary to our findings of negative fractional order in $\left[\mathrm{HClO}_{4}\right]$. Thus, the only choice left is free NBP, which, when considered as the reactive species, leads to a rate law capable of explaining all the kinetic observations and other effects. On the basis of above experimental findings Scheme 1 can be proposed for kinetics of oxidation of L-threonine by NBP in acidic medium.

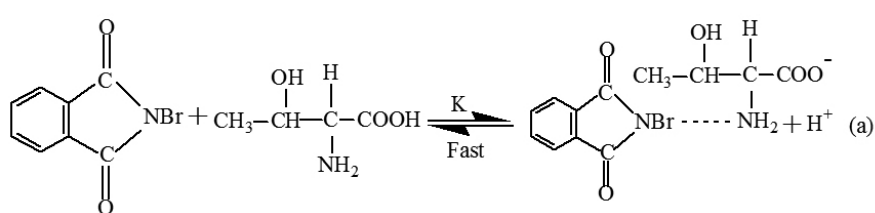

$\left(\mathrm{C}_{1}\right)$<smiles>CC(O)C(N)C(=O)[O-]</smiles>

$\left(\mathrm{C}_{2}\right)$

\section{$\left(\mathrm{C}_{3}\right)$}

Scheme 1. Proposed Mechanism of the oxidation reaction of L-threonine by NBP.

On the basis of the scheme 1, the rate of disappearance of NBP is given as following:

$$
\mathrm{NBP}+\mathrm{S} \rightleftharpoons \mathrm{K} \rightleftharpoons \mathrm{C}+\mathrm{H}^{+}
$$

Where $\mathrm{C}$ is the intermediate compound.

$$
\text { C } \stackrel{\mathrm{k}}{\longrightarrow} \text { Products }
$$

$$
\begin{aligned}
& \text { rate }=\mathrm{k} \mathrm{xC} \\
& \mathrm{K}=\frac{[\mathrm{C}]\left[\mathrm{H}^{+}\right]}{[\mathrm{NBP}][\mathrm{S}]} \\
& \mathrm{C}=\frac{\mathrm{K}[\mathrm{NBP}][\mathrm{S}]}{\left[\mathrm{H}^{+}\right]} \\
& \text {rate }=\frac{\mathrm{kK}[\mathrm{NBP}][\mathrm{S}]}{\left[\mathrm{H}^{+}\right]} \\
& (\mathrm{NBP})_{\mathrm{T}}=(\mathrm{NBP})+(\mathrm{C}) \\
& \text { So rate }=\frac{\mathrm{kK}[\mathrm{NBP}]_{\mathrm{T}}[\mathrm{S}]}{\left[\mathrm{H}^{+}\right]+\mathrm{K}[\mathrm{S}]}
\end{aligned}
$$

The above rate law is in good agreement with the experimental results.

Quantitative treatment of micellar effect. The kinetic results of the effect of varying [CTAB] on the rate of reaction (Table 4) can be explained by means of the pseudo phase model proposed by Berezin's et $\mathrm{al}^{22}$, which takes into consideration solubilization of both reactant into the micellar phase (Scheme 2).

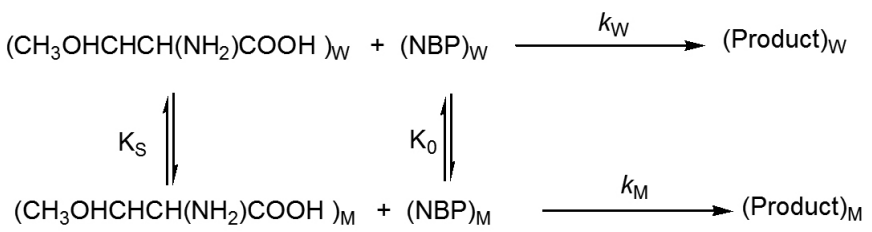

Scheme 2: Reactions taking place as per Berezin pseudo phase model

where $\mathrm{S}$ is substrate and $\mathrm{O}$ is oxidant, $k_{\mathrm{w}}$ is rate constant in aqueous phase, $\mathrm{K}_{\mathrm{S}}$ and $\mathrm{K}_{\mathrm{O}}$ are binding constants of substrate and oxidant with CTAB 
respectively.

Table 4. Effect of $[\mathrm{CTAB}]$ on the Oxidation reaction of [L-threonine] by NBP.

\begin{tabular}{|c|c|}
\hline $\begin{array}{c}{[\mathrm{CTAB}] \times 10^{3}} \\
\mathrm{~mol} . \mathrm{dm}^{-3}\end{array}$ & $\begin{array}{c}k_{\text {obs }} \times 10^{4} \\
\mathrm{~s}^{-1}\end{array}$ \\
\hline 0 & 1.91 \\
\hline 0.5 & 2.54 \\
\hline 1.0 & 2.84 \\
\hline 1.5 & 4.16 \\
\hline 2.0 & 6.92 \\
\hline 2.5 & 11.25 \\
\hline 3.0 & 16.48 \\
\hline 3.5 & 19.35 \\
\hline 4.0 & 19.44 \\
\hline 4.5 & 19.56 \\
\hline 5.0 & 20.01 \\
\hline
\end{tabular}

A quantitative rate expression for a bimolecular reaction occurring only in aqueous $\left(k_{\mathrm{w}}\right.$ path) and micellar ( $k_{\mathrm{M}}$ path) phase for the pseudo-first order rate constant is given below:

$$
k_{\text {obs }}=\frac{k_{\mathrm{W}}+k^{\prime}{ }_{\mathrm{M}} \mathrm{K}_{\mathrm{S}} \mathrm{K}_{0}\left(\mathrm{C}_{\text {surf }}-\mathrm{CMC}\right)}{\left[1+\mathrm{K}_{\mathrm{S}}\left(\mathrm{C}_{\text {surf }}-\mathrm{CMC}\right)\right]\left[1+\mathrm{K}_{0}\left(\mathrm{C}_{\text {surf }}-\mathrm{CMC}\right)\right]}
$$

Where $\mathrm{C}_{\text {Suf }}$ is the analytical concentration of $\mathrm{CTAB}, k^{\prime}=\left(k_{\mathrm{M}} / \mathrm{V}\right), \mathrm{V}$ being molar volume of the micelle and $k_{\mathrm{W}} \& k_{\mathrm{M}}$ are the pseudo-first order rate constants in absence and presence of micelles, respectively. Since the oxidant will be charged species and the substrate is large molecules, the hydrophobic and electrostatic interactions will be large and hence it may be expected that $\mathrm{K}_{\mathrm{S}}$ and $\mathrm{K}_{0}$ will be high.

Since $\mathrm{C}_{\text {Surf }}$ is small it may be possible that $k_{\mathrm{W}}>>k_{\mathrm{M}} \mathrm{K}_{\mathrm{S}} \mathrm{K}_{\mathrm{o}}\left(\mathrm{C}_{\text {surf }}-\mathrm{CMC}\right)$ so that the equation (14) takes the form:

$$
k_{\text {obs }}=\frac{k_{\mathrm{W}}}{1+\mathbb{1}\left(\mathrm{K}_{\rrbracket_{\mathrm{s}}}+\mathrm{K}_{0}\right)\left(\mathrm{C}_{\text {surf }}-\mathrm{CMC}\right)+\mathrm{K}_{\mathrm{s}} \mathrm{K}_{0}\left(\mathrm{C}_{\text {surf }}-\mathrm{CMC}\right)^{2}}
$$

Again, since $\left(\mathrm{C}_{\text {surf }}-\mathrm{CMC}\right)$ is very small, the terms containing $\left(\mathrm{C}_{\text {surf }}-\right.$ $\mathrm{CMC})^{2}$ may be neglected, and the equation (15) may be rearranged to:

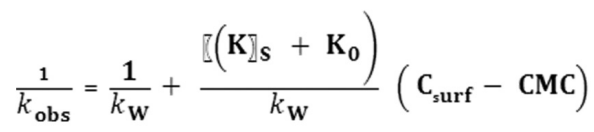

Plot of $k_{\mathrm{obs}}{ }^{-1}$ versus $\left(\mathrm{C}_{\mathrm{Surf}}-\mathrm{CMC}\right)$ for L-threonine is linear (Figure 6 ) with negative slope and positive intercept. The values $\mathrm{K}_{\mathrm{s}}+\mathrm{K}_{\mathrm{o}}=3.73 \times 10^{3} \mathrm{dm}^{3} \mathrm{~mol}^{-1}$.

All micellar-mediated reactions are concluded to occur in the Stern layer ${ }^{23}$. Micellar surfaces are water rich $^{24}$ (activity of the water at the surfaces of ionic micelles is not different from water activity in the aqueous pseudophase). Electrostatic and hydrophobic interactions play an important role in the incorporation/association of substrates into micelles. The positive catalytic effect of CTAB micelles indicates that the NBP and L-threonine may form complex $\mathrm{C}$ at the juncture region (Scheme 1). The complex, having negative charge, may now orient in a manner suitable for continuing the reaction.

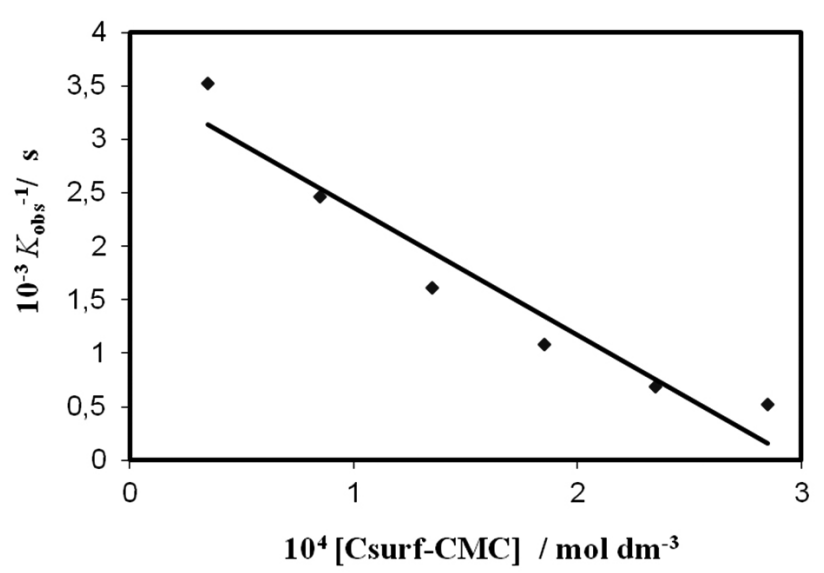

Figure 6. The plot depicting Berezin model with reaction conditions as $[\mathrm{NBP}]=1.0 \times 10^{-4} \mathrm{~mol} \mathrm{dm}^{-3}$, [L-threonine $]=1.0 \times 10^{-3} \mathrm{~mol} \mathrm{dm}^{-3},\left[\mathrm{H}^{+}\right]=1.5 \mathrm{x}$ $10^{-2} \mathrm{~mol} \mathrm{dm}^{-3}\left[\mathrm{Hg}^{++}\right]=2.0 \times 10^{-4} \mathrm{~mol} \mathrm{dm}^{-3},\left[\mathrm{CH}_{3} \mathrm{COOH}\right]=50 \%$, Temperature $=308 \mathrm{~K}$

\section{CONCLUSIONS}

In the light of kinetic observations for the micellar effect on the kinetics of oxidation of L-threonine by $\mathrm{N}$-bromophthalimide in the presence of perchloric acid, the following conclusions can easily be drawn: The reactive species of oxidant NBP is NBP itself. Activation parameters have been evaluated for the oxidation reactions both in absence and in presence of surfactant. In the presence of $\mathrm{CTAB}$, the rate of oxidation first increases and after attaining a peak it remains almost constant with increasing concentration of CTAB. These results are of relevance to variety of applications such as understanding of important biochemical mechanisms and functioning of pharmaceutical formulations involving amino acids.

The micellar effect can be correlated with the nature of the reducing substrate and the reaction conditions. These micellar effects are quite important to understand and to substantiate the proposed mechanistic pathways. Application of the kinetic model confirms the behaviour of micellar-induced oxidation reaction.

\section{ACKNOWLEDGMENT}

One of the authors Mrs. Namita Goyal thanks the Department of Science and Technology, New Delhi for granting the Woman Scientist fellowship and the research project grant (SR/WOS-A/CS-63/2009). We are thankful to reviewers and editor for useful comments and suggestions for improvement in this article.

\section{REFERENCES}

1. J.P. Flatt, United Nations University Press, Protein-Energy Interactions, Amino acid oxidation and food intake Department of Biochemistry and Molecular Biology, University of Massachusetts Medical Center, Worcester, MA 01655, U.S.A., 1991

2. F. Carli, J.D. Webster, D. Halliday, Metabolism 46, 23, (1997)

3. D.E. Richardson, C.A.S. Regino, H.Yao, J.V. Johnson, Free Radical Biology and Medicine 35, 1538, (2003)

4. G. Ionita, V.E. Sahini, G. Semenescu, Acta Chim. Slov. 47, 111, (2000)

5. C. Song, L. Chen, J. Shan, Research Letters in Inorganic Chemistry, Article ID 786857: 4 pages, (2008)

6. T.P. Jose, S.M. Tuwar, Journal of Molecular Structure 827, 137, (2007)

7. H. Shi, S. Shen, H. Sun, Z. Liu, L. Li, Journal of Inorganic Biochemistry 101, 165, (2007)

8. M.H. Penner, R.B. Yamasaki, D.T. Osuga, D.R. Babin, C.F. Meares, R.E. Feeney, Arch. Biochem. Biophys. 225, 740, (1983)

9. R.M. Rodriquez, J.D. Andre's, E. Brillas, J.A. Garrido, J.P. Benito, New J. Chem. 12, 143, (1988)

10. M.Y. Hussain, F. Ahmad, Int. J. Chem. Kinet. 22, 331, (1990)

11. V.K. Sharma, B.H. Bielski, J Inorg. Chem. 30, 4306, (1991)

12. S. Chandraju, K.S. Rangappa, N.M.M. Gowda, Int. J. Chem. Kinet. 31, $525,(1999)$ 
13. R. Pascual, M.A. Herra'ez, Can. J. Chem. 63, 2349, (1985)

14. R.C. Hiremath, S.M. Mayanna, N. Venkatasubramanian, $J$ Chem.Soc., Perkin Trans. II 1569, (1987)

15. M.S. Ramachandran, D. Easwaramoorthy, V. Rajasingh, T.S. Vivekanandam, Bull. Chem. Soc. Jpn., 63, 2397, (1990)

16. M. Z. Barkat, El-Wahab, M.F.A 1954 Anal. Chem. 26, 1973

17. K. J. Laidler, Chemical Kinetics., Pearson Education (Singapore) Pte. Ltd. 193, 2004

18. S. Patil, Y.R. Katre, A.K. Singh, Colloids and Surfaces A: Physicochemical and Engineering Aspects 308, 6, (2007)
19. Y.R. Katre, M. Singh, S. Patil, A.K. Singh, Acta Phys. Chim. Sin. 25(2), $319,(2009)$

20. S. Patil, Y.R. Katre, A.K. Singh, Journal of Surfactants and Detergents. 10, 175, (2007)

21. A. Anjum, P. Srinivas, Asian J. Chem. 17(1), 553, (2005)

22. I.V. Berezin, K. Martinek, A.K. Yatsimirskii, Russ. Chem. Rev. 42, 787, (1973)

23. E.H. Cordes, R.B. Dunlap, Acc. Chem. Res. 2, 329 (1969)

24. F.M. Menger, Acc. Chem. Res. 12, 11, (1979) 